\title{
FIRST LAUNCHING OF THE BRITISH STABILIZED SKYLARK ROCKET
}

\author{
by R. Wrison \\ (Culham Laboratory, Nr. Abingdon, Berkshire, United Kingdom)
}

\begin{abstract}
Rfsumf. - On donne un bref compte rendu du premier lancement d'une fusée Skylark à Woomera, Australie,le 11 août 1964, portant un pointeur automatique de Soleil.

ABstraot. - A brief report is given on the launching of the first Sun pointing stabilized Skylark rocket from Woomera, Australia on August 11 th 1964.
\end{abstract}

Реяюме. - Приведен краткое описание первого запуска ракеты Sкуlarк в Wоомера (Австралия) 11 августа 1964 с прибором автоматической наводки на Солнце.

The first stabilized Skylark rocket was launched from Woomera, Australia at 15.10 hours (local time) on August 11th. This vehicle carried a number of experiments prepared in a combined payload by Culham Laboratory and Leicester University. The three axis stabilization system was developed by Eumotr Bros., Frimley, after initial studies by, and under contract to, R. A. E., Farnborough. The system operates after the rocket motor is detached and points the head along the solar vector by means of gas jets which operate in response to error signals derived from sunsensing photocells. Control in the third axis (roll) is also obtained by gas jets but in this case the error signals are derived from magnetometers.

In addition to this primary stabilization, one of the Culham experiments utilises a fine alignment servo system in which a collector mirror is rotated about two perpendicular axes on gimbal mounts so as to maintain the solar image stationary relative to the slit of a normal incidence vacuum spectrograph. The necessary error signals are derived from a split-field detector which measures the position of the solar image. The system is aligned with the slit tangential to the solar limb and the spectrograph covers the wavelength range 500-2500 $\AA$ with a resolution of about $0.3 \AA$.

Also included in the payload were two grazing incidence spectrographs with metallic filters over the slits for the elimination of scattered light. These operated without collector mirrors and pointed directly to the Sun. The University of Leicester equipment, which was mounted in the apex of the nose cone, consisted of a orystal X-ray spectrograph and a number of $X$-ray pinhole cameras for X-ray solar photography.

A photograph of the full rocket head, set up on the alignment jig, prior to firing, is shown in Plate 1. The split nose cone is absent and the University of Leicester equipment can be seen on top of the heat shield which encloses the Culham equipment and has apertures for viewing the Sun. The assembly includes the electronics, telemetry and parachute bays and, at the foot, the vehicle stabilization unit. The latter is detached at re-entry and the experimental head recovered by parachute return.

During the flight of August 11th, the stabilization worked well, acquiring the Sun 25 seconds after the separation of the motor and the detachment of the split nose cone, and pointed the payload towards the Sun throughout flight to an accuracy of better than 10 minutes of arc. No roll data are yet available. The fine alignment system also operated successfully throughout flight maintaining the solar image to within 10 seconds of arc. Thus the primary purpose of this launching, i.e. the testing of the stabilization system, was achieved.

Although the parachute failed to open, the photographic cassettes were recovered intact but for reasons being investigated a number of the films were fogged. However, a successful spectrum was obtained between $1000-2500 \AA$ with a rather short exposure time of about 15 seconds, together with X-ray solar photographs obtained with the Leicester pinhole cameras. The ultraviolet spectrum shows Lyman $\alpha$ and the OVI reso- 
nance lines at $1031 \AA$ together with a mainly Fraunhoffer spectrum from 2000-2500 $\AA$. The length of spectral lines recorded confirm that the slit was set on the solar limb.

Detailed solar studies in the ultraviolet and $\mathrm{X}$-ray regions of the spectrum require as an essential basic facility a stabilized platform above the atmosphere. This flight has demonstrated the capabilities of the first such British system and is the beginning of a series of solar studies, planned through the British National Committee for Space Research and will also, I hope, accelerate the development of this field of research within ESRO.

Manuscrit reçu le 2 octobre 1964. 